PAPER

\title{
Premorbid cognitive testing predicts the onset of dementia and Alzheimer's disease better than and independently of APOE genotype
}

\author{
J Cervilla, M Prince, S Joels, S Lovestone, A Mann
}

J Neurol Neurosurg Psychiatry 2004;75:1100-1106. doi: 10.1136/jnnp.2003.028076

See end of article for authors' affiliations

Correspondence to:

Professor M Prince

Epidemiological

Psychiatry, Institute of

Psychiatry, De Crespigny

Park, London SE5 8AF,

UK; m.prince@

iop.kcl.ac.uk

Received

16 September 2003

Revised 9 November 2003

Accepted

14 November 2003
Objective: To determine whether a cognitive test package can predict the onset of dementia up to 11 years later, and the extent to which this prediction is independent of that provided by APOE genotype.

Methods: Prospective cohort study based on 54 general practices in the UK; 657 survivors of the 1088 participants in the MRC treatment trial of hypertension in older adults were followed for up to 11 years; 370 participants (57\% of survivors) were traced, screened for dementia, and genotyped for APOE in 1994. Baseline assessments included trail making test A, paired associated learning test, Raven's progressive matrices, and national adult reading test. At follow up, both mini-mental state examination and CAMCOG were used. Outcome measures were DSM-IIIR dementia and NINCDS-ADRDA possible and probable Alzheimer's disease.

Results: All the cognitive tests completed in 1983 predicted onset of dementia and Alzheimer's disease up to 11 years later, as did APOE genotype. Cognitive test performance was not associated with APOE genotype. Addition of cognitive tests increased the area under the ROC curve for the prediction of Alzheimer's disease provided by age, family history, and APOE genotype $(0.81 \vee 0.69, p=0.048)$; addition of APOE genotype did not increase the area under the ROC curve for the prediction provided by age, family history, and cognitive tests $(0.81 \vee 0.77, p=0.28)$.

Conclusions: Simple tests of cognitive ability provide useful predictive information up to a decade before the onset of dementia. The predictive information provided is independent of, but not enhanced by, the addition of APOE genotype.
$\mathrm{T}$ ue predictive tests for dementia and Alzheimer's disease, which are the focus of the current analysis, differ from confirmatory or screening tests in that at the time when the tests are applied the disease is not diagnosable by standard procedures, and its clinical features cannot be discerned. However, the underlying pathological process may already have been set in train, markers of this process may be apparent, salient risk exposures may be measured, and the diagnosis may thus have the potential to be brought forward in time (fig 1). The clinical rationale for predictive tests is that, at least hypothetically, a critical period for intervention may lie between the earliest point at which the diagnosis can be made (point 1 in fig 1 ) and the time at which diagnosis is currently made (point 2). Of course if the critical period for intervention falls after point 2 , or before point 1 , then there would be no point in advancing the diagnosis. Evidence suggests that the pathological features of Alzheimer's disease are already well advanced at the time when the diagnosis is made. ${ }^{1}$ Current pro-cholinergic pharmacotherapies appear to be purely symptomatic, but compounds with the potential to slow disease course may be developed in the future. Such compounds are likely to have maximum efficacy when applied before extensive and irremediable damage has occurred, and hence before the disease is clinically manifest. While several studies have indicated that cognitive tests can provide a moderate degree of prediction for dementia, ${ }^{2}$ few have investigated prediction over a longer period, within which the critical period for intervention may lie. ${ }^{34}$

In the Medical Research Council trial of treatment of hypertension in older adults ${ }^{5}$ (henceforward referred to as the MRC trial), a cognitive test battery was administered to all participants on recruitment in 1983 or 1984, and dementia was an exclusion criterion. We showed that a simple test package-derived from cognitive test performance, age, and a family history of dementia-was a useful predictor of dementia onset over the first eight years of follow up. ${ }^{6}$ Three years later we returned to the same cohort, aiming to identify newly incident cases of dementia and to determine the APOE genotype. The questions to be addressed were as follows:

- Do cognitive tests completed in 1983 continue to predict onsets of dementia up to 12 years later?

- Is the prediction by cognitive tests independent of APOE genotype?

- Does knowledge of APOE genotype add usefully to the predictive power of a test package based upon age, family history of dementia, and cognitive test performance?

\section{METHODS}

\section{Study design and participants}

The individuals included in this analysis had all been recruited into the MRC trial between 1983 and 1984. ${ }^{5}$ Dementia status was assessed in 1991 for the purposes of a dementia case-control study, ${ }^{7}$ and finally again in $1994 .{ }^{8}$ The methods used in each of these studies have already been described in the referenced publications. In brief, the MRC

Abbreviations: AGECAT, aged geriatric examination computerassisted taxonomy; CAMCOG, Cambridge cognitive examination; GMS, geriatric mental state; MMSE, mini-mental state examination; NART, new adult reading test; NINCDS-ADRDA, National Institute of Neurological and Communicative Disorders and Stroke-Alzheimer's Disease and Related Disorders Association; PALT, paired associate learning test; RPM, Raven's progressive matrices; ROC, receiver operating characteristic; TMT, trail making test 


\begin{tabular}{|c|c|c|c|c|}
\hline $\begin{array}{l}\text { Pathological } \\
\text { onset of } \\
\text { dementia }\end{array}$ & $\uparrow$ & $\begin{array}{l}\text { Earliest possible } \\
\text { dementia } \\
\text { diagnosis }\end{array}$ & $\uparrow$ & $\begin{array}{l}\text { Current dementia } \\
\text { diagnosis }\end{array}$ \\
\hline $\begin{array}{l}\text { Critical } \\
\text { intervention } \\
\text { points }\end{array}$ & 1 & & 2 & \\
\hline
\end{tabular}

Predictive tests may be justified if the critical opportunity for intervention lies at point 2 rather than points 1 or 3

Figure 1 Potential clinical use of predictive tests for dementia. Predictive tests may be justified if the critical opportunity for intervention lies at point 2 rather than at points 1 or 3.

trial compared mortality and morbidity among 4396 subjects randomised to receive a $\beta$ blocker, a thiazide diuretic, or placebo. ${ }^{5}$ Inclusion criteria were age 65 to 75 years and systolic blood pressure 160 to $209 \mathrm{~mm} \mathrm{Hg}$. Those with serious intercurrent illnesses, including dementia, were excluded. Participants were recruited in 226 United Kingdom MRC general practice research framework practices. Invitations for screening had been sent to all registered patients within the eligible age range. In 1991 we reviewed a subsample of 1545 participants from 71 of the 226 practices in an attempt to ascertain all cases of dementia and Alzheimer's disease incident since the beginning of the MRC trial. ${ }^{7}$ In 1994 we updated this procedure by aiming to screen all surviving participants from the practices included in the earlier casecontrol study. ${ }^{7}$ In the event, 54 practices were still attached to the MRC GP framework and were willing to take part in the follow up.

As previously reported, ${ }^{8}$ of the initial cohort of 1088 subjects recruited in these 54 practices, 431 had died; of the 657 survivors, $158(24 \%)$ declined to participate in the follow up survey, and $112(17 \%)$ had moved away from their research practice; thus 387 subjects participated and blood samples were obtained from 370, constituting $56 \%$ of survivors and $34 \%$ of the entire cohort. Figure 2 shows a summary of the sampling process. Those successfully followed up in 1994 differed systematically from those who had refused to participate, who tended to have lower premorbid intelligence and poorer performance on cognitive tests at entry to the trial than did other groups. The mean (SD) age of the achieved sample was 80.1 (2.9) years (range 74.2 to 85.6$)$ at the mid-point of the re-survey.

\section{Dementia diagnosis in 1994}

We used a standard three stage dementia diagnosis procedure. The MRC research nurse first administered the minimental state examination (MMSE) ${ }^{9}$ to all consenting participants. All those who scored less than 25/30, and all those educated beyond the age of 16 who scored less than 27/ 30 , were selected for the second stage. A research psychiatrist visited the practice to make a dementia diagnostic assessment comprising the GMS/AGECAT clinical interview, ${ }^{10}$ the CAMCOG cognitive test battery, ${ }^{11}$ and a brief standardised neurological examination. ${ }^{12}$ A structured assessment of the onset and course of the disorder, consistent with current dementia subtype diagnostic criteria, was administered to an informant who knew the participant well. Diagnoses were allocated by a consensus panel of old age psychiatrists applying standard research diagnostic criteria for dementia, ${ }^{13}$ possible and probable Alzheimer's disease, ${ }^{14}$ and vascular dementia. ${ }^{15}$ For the 370 participants with complete data, the consensus panel assigned diagnoses as follows: 18 (4.9\%) probable Alzheimer's disease, six (1.6\%) possible Alzheimer's disease, five (1.4\%) vascular dementia, one $(0.3 \%)$ mixed dementia (Alzheimer's disease with vascular dementia), four $(0.8 \%)$ dementia subtype unspecified, and seven (1.9\%) borderline cases with no clear consensus on diagnosis. The prevalence of Alzheimer's disease in this sample was therefore $6.5 \%$, and the prevalence of dementia $9.0 \%$, or $10.9 \%$ including borderline cases.

\section{APOE genotype}

APOE genotype was determined from blood samples obtained from consenting survivors during the course of the 1994 follow up. ${ }^{8}$ The frequencies of the APOE genotypes in the whole sample were as follows: $2 / 2$, three $(0.8 \%) ; 2 / 3$, 40 (10.8\%); 3/3, 221 (59.7\%); 2/4, seven (1.9\%); 3/4, 97 $(26.2 \%)$; and $4 / 4$, two $(0.5 \%)$. Therefore $28.6 \%$ had one or more $\epsilon 4$ alleles, $59.6 \%$ were $\epsilon 3 / 3$, and $11.6 \%$ were $\epsilon 2 / 2$ or $2 / 3$. The APOE genotype was strongly associated with both dementia and Alzheimer's disease diagnoses in 1994. ${ }^{8}$ The prevalence of all dementia rose from $4.7 \%$ among those with a $2 / 2$ or $2 / 3$ genotype to $9.0 \%$ for those with $3 / 3$ and $17.0 \%$ for those with any e 4 allele $\left(\chi^{2}=6.3, p=0.012\right)$. For NINCDS/ ADRDA probable and possible Alzheimer's disease, the association was even stronger, with a prevalence of $2.4 \%$ among those with a $2 / 2$ or $2 / 3$ genotype, rising to $4.7 \%$ for those with $3 / 3$ and $12.9 \%$ for those with any e4 allele $\left(\chi^{2}=7.6, \mathrm{p}=0.006\right)$.

\section{The predictive test variables}

Assessment of cognitive function at entry to the MRC trial

The following assessments were used:

The paired associate learning test (PALT). ${ }^{16}$ This tests the capacity to recall the second half of a pair of words cued by the first half of the couplet, thus addresses episodic memory.

The trail making test (TMT), part A. ${ }^{17}$ This tests attention, concentration, and psychomotor function. Subjects are timed while they join consecutive numbers, arranged at random.

The new adult reading test (NART). ${ }^{18}$ This is a stable measure of premorbid (crystallised) intelligence.

Raven's progressive matrices (RPM) parts A and B. ${ }^{19}$ These are tests of non-verbal (fluid) intelligence, sensitive to age related cognitive decline.

All tests were administered by MRC general practice research framework research nurses who had been specifically trained for the purpose. The PALT and the TMT were administered repeatedly through the MRC trial; the mean of the entry and one month assessments was used in this analysis. The NART and RPM were measured at entry to the trial only.

\section{Family history of dementia}

Family history of dementia was assessed from a questionnaire administered both to the subject and to a reliable informant in the 1994 follow up study. Vital status, current ages or ages at death, and dementia histories were systematically ascertained for all first degree relatives. A family history of dementia loading was derived taking into account both the numbers of relatives affected and the family personyears at risk for the disease. ${ }^{8}$

\section{Analysis}

To assess the likely independence of the prediction of dementia onset by the cognitive tests from that provided by APOE genotype, we first assessed the association between APOE and each of the four cognitive tests using one way ANOVA, with $\xi^{2}$ as a measure of the effect size for the association. We used identical analyses to assess the associations between APOE genotype and both age and family history of dementia loading. 


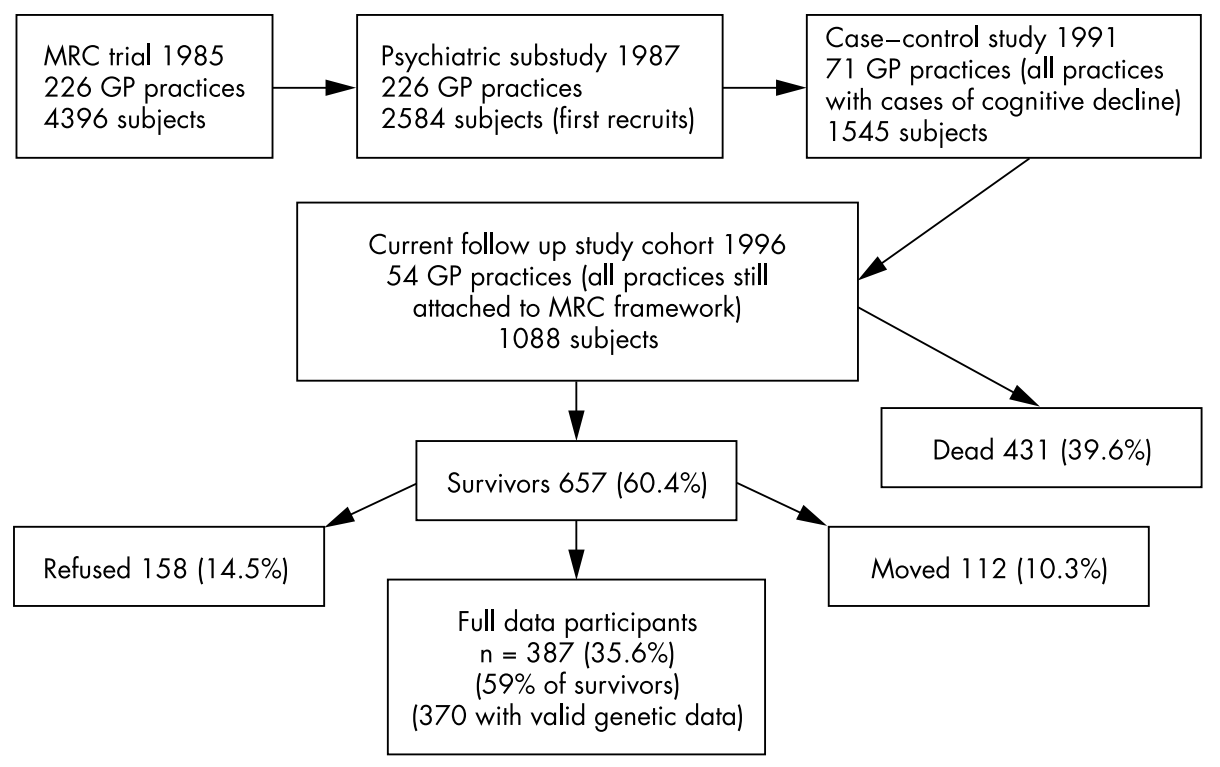

Figure 2 The MRC elderly hypertension trial psychiatric substudy cohort follow up.

We then compared mean entry (1983) cognitive test scores for those who were and were not found to have dementia or Alzheimer's disease at the 1994 follow up. Given the long follow up period, we explored heterogeneity of prediction by time of onset by stratifying 1994 dementia cases into two groups according to onset before or after the first 1991 follow up. Identical analyses were carried out for the family history of dementia loading and for age. To facilitate comparison of discrimination between tests, all mean differences were standardised, expressed as a proportion of the standard deviation of the relevant variable. Predicted standardised mean differences between dementia cases and non-cases are also presented after adjusting for APOE genotype, and after adjusting for years of education.

We next predicted probabilities of Alzheimer's disease and dementia caseness for each participant from the following logistic regression models:

- Age and family history of dementia loading

- Age and family history of dementia loading and APOE genotype

- Age and family history of dementia loading and cognitive tests

- Age and family history of dementia loading and cognitive tests and APOE genotype

For the purposes of these analyses the distribution of each cognitive test, and of age and family history loading, was divided into thirds, and APOE genotype into $2 / 2$ or $2 / 3,3 / 3$, and $4 /^{*}$. The sample was divided into tenths according to subjects' predicted probability of caseness, and the sensitivity and specificity for the diagnosis calculated at each decile cut off point. Sensitivity was then plotted against 1 -specificity (false positive rate) to produce a receiver operating characteristic (ROC) curve. Using non-parametric procedures, ${ }^{20}$ the area under each curve was calculated, with 95\% confidence intervals, as an overall measure of the discriminability of the test package. The discriminability of pairs of test packages was compared statistically using $z$ tests. ${ }^{21}$ For both dementia and Alzheimer's disease we compared test packages $2 v 1,3 v 1$, and $3 v 4$. All ROC analyses were carried out using ROC Analyzer software. ${ }^{22}$

\section{RESULTS}

Association between APOE genotype and cognitive test performance in 1983

None of the cognitive tests completed in 1983 before any of the participants had gone on to develop dementia was associated to any degree with APOE genotype (table 1). There was also no association in subgroups consisting of those who did and did not go on to develop dementia. There was a nonsignificant trend for an association between APOE genotype and both age and family history of dementia loading in the direction $2 / 2$ or $2 / 3$ (oldest, and lowest family history loading), $3 / 3$ (intermediate), and $4{ }^{\star}$ (youngest, and highest loading).

\section{Associations between cognitive test performance in 1983 and dementia onset by 1994}

Each of the cognitive tests completed at entry to the MRC trial in 1983 predicted onset of dementia and Alzheimer's disease by 1994, with poorer test performance among those who went on to develop dementia (table 2). Patterns of prediction were similar for the 41 dementia cases and the subset of 24 Alzheimer's disease cases. Likewise, patterns of prediction were similar for the seven cases of dementia with onset between 1983 and the 1991 follow up, and the 34 with onset between 1991 and 1994 (results not shown). The TMT-A gave the most marked discrimination, with around 0.6 SD difference between baseline times for test completion. Next came the two tests of general intelligence, the NART (crystallised intelligence) and RPM (fluid intelligence), each with around 0.5 SD difference, and the PALT with 0.25 SD difference. The difference on the PALT was not statistically significant at the $5 \%$ level. Given that PALT scores, unlike the other cognitive tests, were heavily negatively skewed, with $35 \%$ of subjects scoring the maximum of 18 at baseline and one month assessments, we also tested using the nonparametric Mann-Whitney procedure for associations with dementia onset $(p=0.26)$ and Alzheimer's disease onset $(\mathrm{p}=0.70)$.

The standardised mean differences on the four cognitive tests between those experiencing and those not experiencing a later onset of dementia were little altered after adjusting for APOE genotype (table 2). The findings for the adjusted mean 
Table 1 Associations between APOE genotype and cognitive test scores (1983), age, and family history of dementia

\begin{tabular}{lllllll}
\hline & $\begin{array}{l}\text { APOE } \mathbf{2} / \mathbf{2} \text { or } \\
\mathbf{2} / \mathbf{3}(\mathbf{n}=\mathbf{4 3})\end{array}$ & $\begin{array}{l}\text { APOE } \mathbf{3} / \mathbf{3} \\
\mathbf{( n = 2 2 1 )}\end{array}$ & $\begin{array}{l}\text { APOE } \mathbf{4} / /^{*} \\
(\mathbf{n}=\mathbf{1 0 6})\end{array}$ & $\xi^{\mathbf{2}}$ & $\mathbf{F}$ value (\%) & $\mathbf{p}$ Value \\
\hline TMT-A & $50.1(14.8)$ & $51.6(20.5)$ & $50.5(19.4)$ & 0.1 & 0.2 & 0.84 \\
PALT & $17.0(1.1)$ & $17.0(1.3)$ & $17.1(1.1)$ & 0.1 & 0.2 & 0.80 \\
RPM & $16.5(3.3)$ & $16.1(3.9)$ & $16.1(4.0)$ & 0.1 & 0.2 & 0.85 \\
NART & $31.6(11.0)$ & $31.3(10.8)$ & $31.8(10.7)$ & 0.0 & 0.1 & 0.93 \\
Age & $70.7(2.8)$ & $70.2(2.9)$ & $69.8(2.6)$ & 1.0 & 1.8 & 0.17 \\
Family history of & & & & & & \\
dementia loading & $0.80(0.13)$ & $0.82(0.13)$ & $0.85(0.12)$ & 1.0 & 1.9 & 0.15 \\
\hline
\end{tabular}

NART, new adult reading test; PALT, paired associate learning test; RPM, Raven's progressive matrices; TMT-A, trail making test $A$.

differences between Alzheimer's disease cases and non-cases were similar (results not shown). After adjusting for years of education, mean differences on the RPM and NART were somewhat attenuated and no longer statistically significant at the 5\% level; TMT-A was little affected.

The odds ratios for the independent associations of the test variables with dementia outcome for three of the four predictive models are given in table 3 . These three models form a hierarchy, and tests of statistical significance were done for each block. Family history and age were minimally predictive. The four cognitive tests made the largest contribution, with TMT-A predominating and PALT showing a very weak non-significant trend for higher risk with better test performance. APOE genotype still predicted dementia onset $\left(\chi^{2}=6.8,2 \mathrm{df} ; \mathrm{p}=0.03\right)$ after adjusting for age, family history of dementia, and cognitive test scores in 1983. Results for prediction of Alzheimer's disease onset were similar and are not shown in detail: age and family history were again little associated $\left(\chi^{2}=3.3,4 \mathrm{df} ; \mathrm{p}=0.51\right)$; cognitive tests were strongly associated $\left(\chi^{2}=19.7,8 \mathrm{df} ; \mathrm{p}=0.01\right)$ although again the PALT made little independent contribution; and APOE genotype predicted Alzheimer's disease onset $\left(\chi^{2}=9.7,2 \mathrm{df}\right.$; $\mathrm{p}=0.008$ ) somewhat more robustly than it had predicted dementia onset. The ROC curves for each of the four predictive models are given for dementia (fig 3) and Alzheimer's disease (fig 4).

\section{DISCUSSION}

While several studies ${ }^{23-28}$ have reported the ability of tests of cognitive ability to predict the onset of dementia in the short term, few have studied this phenomenon over a period of 10 years. ${ }^{3}$ The large majority of our dementia cases experienced an onset of the condition seven years or more after the tests were administered. This is also the first community based study to look at the combined effect of cognitive tests and APOE genotype in predicting dementia.
Cognitive tests completed in 1983, when all subjects were free of dementia, predicted robustly which among those who survived went on to develop dementia by 1994. We used APOE as a potential predictive factor not only for Alzheimer's disease but for dementia too, given that in 1994 there was uncertainty about the specificity of the association between APOE and Alzheimer's disease. In our previous report, we found that APOE associated increasingly strongly to dementia, possible Alzheimer's disease, and probable Alzheimer's disease, respectively. ${ }^{8}$ APOE genotype was also a strong predictor of dementia onset, and this prediction was independent of that provided by cognitive tests, and vice versa. All predictive models showed greater discriminability for the specific outcome of Alzheimer's disease compared with all dementia. Despite the mutual independence of these predictive factors, the areas under the ROC curvessummarising the overall prediction provided by the tests (that is, the greater the area under the curve the better is the test)-were increased to a statistically significant degree when cognitive tests were added to a test package consisting of age and family history of dementia alone, but not when the same test package was extended by the inclusion of APOE genotype. Likewise the area under the ROC curve for age, family history of dementia, and APOE genotype was significantly increased by the addition of cognitive tests, but the ROC curve for age, family history of dementia, and cognitive tests was not significantly increased by the addition of APOE genotype. Thus APOE genotype, although an independent predictor, in practice added little if anything to the discriminability of a test package based upon simple tests of cognitive function administered well before the onset of dementia.

This was a relatively small sample, and an unusual one given the age and high blood pressure levels of all participants, so our results may not reflect the findings expected in a non-hypertensive population. The fact that our

Table 2 Standardised mean differences on cognitive tests

\begin{tabular}{|c|c|c|c|c|c|c|c|}
\hline & $\begin{array}{l}\text { All dementia } \\
(n=41)\end{array}$ & $A D(n=24)$ & $\begin{array}{l}\text { No dementia } \\
(n=346)\end{array}$ & $A D$ v no dementia* & $\begin{array}{l}\text { Dementia v no } \\
\text { dementia* }\end{array}$ & $\begin{array}{l}\text { Dementia } v \text { no dementia } \\
\text { adjusted for APOE } \\
\text { genotype* }\end{array}$ & $\begin{array}{l}\text { Dementia } v \text { no } \\
\text { dementia adjusted for } \\
\text { years of education* }\end{array}$ \\
\hline TMT-A & $61.8(19.1)$ & $60.9(15.4)$ & $49.8(19.2)$ & 0.58 (0.17 to 0.99$)$ & $0.62(0.30$ to 0.94$)$ & $0.61(0.27$ to 0.93$)$ & $0.53(0.21$ to 0.85$)$ \\
\hline PALT & $16.7(1.5)$ & $16.7(1.7)$ & $17.0(1.2)$ & $0.26-0.16$ to 0.67$)$ & $0.24(-0.09$ to 0.56$)$ & $0.27(-0.06$ to 0.60$)$ & $0.15(-0.18$ to 0.48$)$ \\
\hline RPM & $14.8(3.9)$ & $14.6(3.8)$ & $16.3(3.8)$ & $0.43(0.02$ to 0.85$)$ & $0.39(0.07$ to 0.71$)$ & $0.41(0.08$ to 0.74$)$ & $0.22(-0.08$ to 0.53$)$ \\
\hline NART & $27.6(11.9)$ & $26.3(12.2)$ & $31.9(10.6)$ & $0.52(0.10$ to 0.95$)$ & 0.40 (0.08 to 0.73$)$ & $0.40(0.07$ to 0.73$)$ & $0.22(-0.08$ to 0.52$)$ \\
\hline Age & $70.3(2.9)$ & $70.2(3.0)$ & $70.1(2.8)$ & $0.01(-0.40$ to 0.42$)$ & $0.08(-0.27$ to 0.42$)$ & $0.20(-0.14$ to 0.54$)$ & $0.27(-0.06$ to 0.60$)$ \\
\hline $\begin{array}{l}\mathrm{FH} \text { of dementia } \\
\text { loading }\end{array}$ & $0.86(0.12)$ & $0.85(0.14)$ & $0.82(0.13)$ & $0.23(-0.23$ to 0.62$)$ & $0.27(-0.06$ to 0.60$)$ & $0.10(-0.24$ to 0.43$)$ & $0.00(-0.33$ to 0.34$)$ \\
\hline
\end{tabular}

Values are mean (SD), or *mean (95\% confidence interval).

AD, Alzheimer's disease; FH, family history; NART, new adult reading test; PALT, paired associate learning test; RPM, Raven's progressive matrices; TMT-A, trail making test $A$. 
Table 3 Odds ratios for independent associations between test variables and dementia generated from logistic regression models used to predict probabilities of dementia caseness

\begin{tabular}{|c|c|c|c|c|}
\hline \multirow[b]{2}{*}{ Tests+ } & & \multirow{2}{*}{$\begin{array}{l}\text { Model } 1 \\
\text { FH+Aget }\end{array}$} & \multirow{2}{*}{$\begin{array}{l}\text { Model } 2 \\
\text { FH+Age+Cognitive tests } t\end{array}$} & \multirow{2}{*}{$\begin{array}{l}\text { Model } 3 \\
\text { FH+Age }+ \text { Cognitive tests }+ \text { APOE } \\
\text { genotype } †\end{array}$} \\
\hline & & & & \\
\hline $\mathrm{FH}$ & $<0.78$ & 1 & & \\
\hline Loading & $\begin{array}{l}0.79 \text { to } 0.89 \\
0.90 \text { to } 1.00\end{array}$ & $\begin{array}{l}1.40(0.57 \text { to } 3.46) \\
2.12(0.90 \text { to } 4.97)\end{array}$ & $\begin{array}{l}1.43(0.56 \text { to } 3.68) \\
2.31(0.94 \text { to } 5.65)\end{array}$ & $\begin{array}{l}1.34(0.51 \text { to } 3.49) \\
2.18(0.88 \text { to } 5.43)\end{array}$ \\
\hline Age (years) & $\begin{array}{l}65.0 \text { to } 68.9 \\
69.0 \text { to } 71.8 \\
71.9 \text { to } 75.0\end{array}$ & $\begin{array}{l}1 \\
1.44(0.64 \text { to } 3.23) \\
1.10(0.47 \text { to } 2.62)\end{array}$ & $\begin{array}{l}1.60(0.68 \text { to } 3.75) \\
0.99(0.40 \text { to } 2.45)\end{array}$ & $\begin{array}{l}1.71(0.72 \text { to } 4.04) \\
1.13(0.45 \text { to } 2.83)\end{array}$ \\
\hline TMT-A & $\begin{array}{l}<40 \mathrm{~s} \\
40 \text { to } 56 \mathrm{~s} \\
>56 \mathrm{~s}\end{array}$ & & $\begin{array}{l}1 \\
3.30(1.00 \text { to } 10.8) \\
4.78(1.48 \text { to } 15.4)\end{array}$ & $\begin{array}{l}3.49(1.05 \text { to } 11.6) \\
4.93(1.51 \text { to } 16.8)\end{array}$ \\
\hline PALT & $\begin{array}{l}<17 \\
17 \text { or } 17.5 \\
18\end{array}$ & & $\begin{array}{l}1 \\
1.16(0.46 \text { to } 2.92) \\
1.24(0.47 \text { to } 3.24)\end{array}$ & $\begin{array}{l}1.15(0.45 \text { to } 2.94) \\
1.24(0.47 \text { to } 3.30)\end{array}$ \\
\hline RPM & $\begin{array}{l}<14 \\
14 \text { to } 17 \\
18 \text { to } 24\end{array}$ & & $\begin{array}{l}1 \\
0.39(0.17 \text { to } 0.90) \\
0.40(0.15 \text { to } 1.04)\end{array}$ & $\begin{array}{l}0.41(0.17 \text { to } 0.97) \\
0.42(0.16 \text { to } 1.11)\end{array}$ \\
\hline NART & $\begin{array}{l}<27 \\
27 \text { to } 37 \\
38 \text { to } 50\end{array}$ & & $\begin{array}{l}1 \\
0.74(0.31 \text { to } 1.78) \\
0.75(0.28 \text { to } 2.00)\end{array}$ & $\begin{array}{l}0.69(0.28 \text { to } 1.70) \\
0.70(0.26 \text { to } 1.90)\end{array}$ \\
\hline APOE & $\begin{array}{l}2 / 2 \text { or } 2 / 3 \\
3 / 3 \\
4 /^{*}\end{array}$ & & & $\begin{array}{l}1 \\
1.66(0.36 \text { to } 7.78) \\
4.00(0.84 \text { to } 19.0)\end{array}$ \\
\hline Step $\chi^{2}$ & & $\begin{array}{l}4.0(4 \mathrm{df}) \\
p=0.40\end{array}$ & $\begin{array}{l}21.3(8 \mathrm{df}) \\
p=0.006\end{array}$ & $\begin{array}{l}6.8(2 \mathrm{df}) \\
p=0.03\end{array}$ \\
\hline Model $\chi^{2}$ & & $\begin{array}{l}4.0(4 \mathrm{df}) \\
p=0.40\end{array}$ & $\begin{array}{l}25.3(12 d f) \\
p=0.01\end{array}$ & $\begin{array}{l}32.2(14 \mathrm{df}) \\
0.004\end{array}$ \\
\hline
\end{tabular}

tWith $95 \%$ confidence intervals.

$\mathrm{FH}$, family history; NART, new adult reading test; PALT, paired associate learning test; RPM, Raven's progressive matrices; TMT-A, trail making test A.

sample comprised subjects with mild hypertension may also explain the unexpected finding of an absence of an association between our episodic memory test (the PALT) and cases of dementia, although our finding replicates a previous study that also indicated such lack of association. ${ }^{29}$ Furthermore, the strength of the association that we observed between APOE genotype and both dementia and Alzheimer's disease was consistent with that reported by many other previous studies; hence it is unlikely that our conclusions are undermined either by sampling error or by an unusually weak level of association in aged hypertensive subjects. Bias was also unlikely, given that the assessment of cognitive function was carried out blind to APOE status, and vice versa, and both assessments were carried out blind to dementia outcome. Additionally, we cannot rule out the possibility that our screening process may have resulted in false negatives - that is, people with dementia who were not detected by the screening procedure and who might have interfered with our final results. However, we did reinterview thoroughly all possible cases using a high MMSE cut off point of 25 (27 if highly educated) in order to minimise false negatives as a result of our screening.

Why do tests of cognitive ability predict dementia onset over 11 years, and why is this prediction independent of APOE genotype? It is tempting to conclude that subtle premorbid impairment of cognitive ability represents a decline from a previous level of functioning, and is an early marker of the pathological process of Alzheimer's disease that begins well in advance of the clinical onset. ${ }^{1}$ However, if cognitive decline is an integral component of the dementia syndrome, how can APOE genotype be a direct risk factor for
Alzheimer's disease and yet not be associated with incipient cognitive decline? Our findings in this respect concur with other evidence-many studies have failed to find an association between APOE and global cognitive decline. ${ }^{30-32}$ Positive reports for such an association do exist but they have been found to be weak ${ }^{33}$ or circumscribed to specific areas of cognitive decline, mostly semantic memory. ${ }^{35}$ The model that we have posited, which supposes a continuum between cognitive decline and dementia, cannot be made to fit these observations. An alternative and perhaps more parsimonious explanation is that premorbid tests of cognitive ability are stable markers of early intellectual development-a process that, at least in infants, seems not to be influenced by APOE. ${ }^{31} 32$

Intellectual development may be related to risk for dementia by one of two processes. First, well developed brains with a richly complex cortical synaptic architecture may be intrinsically less likely to sustain Alzheimer's disease pathology and the precipitous decline in cognitive ability that accompanies it. ${ }^{36}$ This theory is supported by the findings from the nuns' study, in which idea density ascertained from biographies written at the age of 18 was negatively associated not only with late life cognitive impairment in vivo, but also with the density of neurofibrillary tangles at necropsy. ${ }^{37}$ Second, in the course of the pathological process of Alzheimer's disease, cognitive or neuronal reserve may delay the onset of clinically relevant cognitive and functional impairment, a theory advanced to explain the consistent observation of a lower risk of dementia among intelligent and well educated people. ${ }^{38}$ This "reserve hypothesis" predicts more advanced Alzheimer's disease pathology among the 


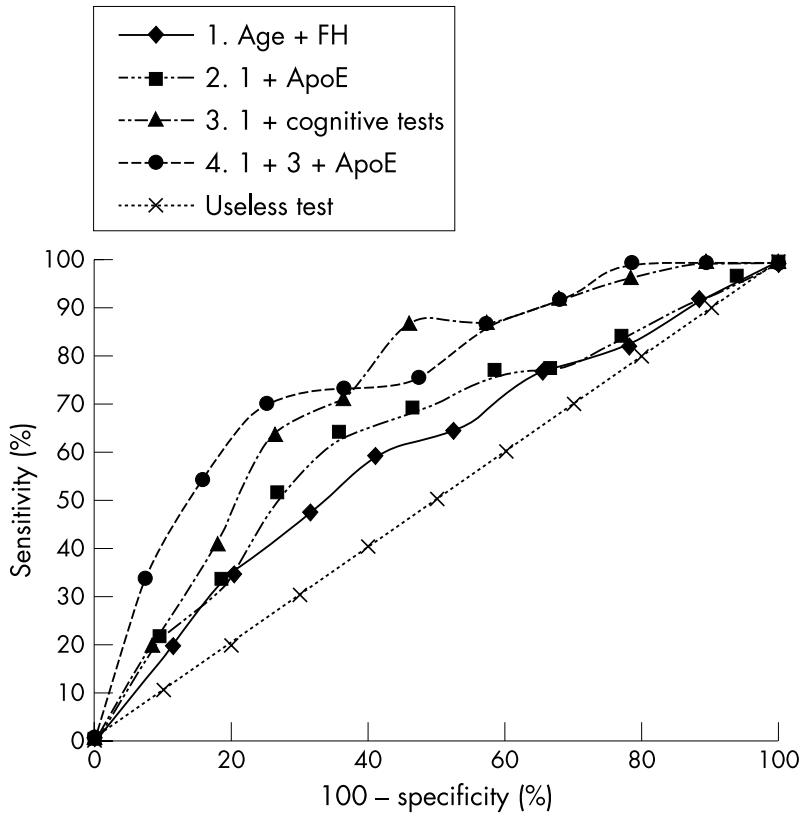

\begin{tabular}{|c|c|c|}
\hline Predictive model & $\operatorname{AUC}(95 \% \mathrm{Cl})$ & Significance test \\
\hline 1. $\mathrm{FH}+$ age & $0.60(0.50$ to 0.70$)$ & \\
\hline $\begin{array}{l}\text { 2. } \mathrm{FH}+\text { age }+ \\
\text { APOE genotype }\end{array}$ & 0.65 (0.59 to 0.74$)$ & $2 v 1: p=0.26$ \\
\hline $\begin{array}{l}\text { 3. } \mathrm{FH}+\text { age }+ \\
\text { cognitive tests }\end{array}$ & $0.74(0.67$ to 0.81$)$ & $\begin{array}{l}3 \vee 1: p=0.015 \\
3 v 2: p=0.069\end{array}$ \\
\hline $\begin{array}{l}\text { 4. } \mathrm{FH}+\text { age }+ \\
\text { cognitive tests }+ \\
\text { APOE genotype }\end{array}$ & $0.77(0.69$ to 0.85$)$ & $\begin{array}{l}4 \vee 3: p=0.28 \\
4 \vee 2: p=0.026\end{array}$ \\
\hline
\end{tabular}

Figure 3 Receiver operating curve (ROC) analysis: the prediction of dementia onset. Areas under the ROC curves (AUC) for each model predicting dementia and tests for the significance of the differences between them.

better educated for any given clinical stage of dementia, and is lent support by the finding of increased mortality in better educated persons with dementia, after adjusting for clinical dementia staging. ${ }^{39}$ APOE genotype might then exert its effect through a different pathway, for example modifying the cumulative impact of a variety of brain insults sustained across the life course. ${ }^{40}$

Our research suggests that predictive tests for Alzheimer's disease and other dementias may be an achievable objective, even with existing technologies. Ascertainment of APOE genotype seems to confer no advantage over lower technology cognitive test packages, and earlier cautions against the indiscriminate use of genotyping as a diagnostic or predictive procedure are well founded. ${ }^{41}{ }^{42}$ Computed tomography or magnetic resonance imaging, particularly if applied sequentially, ${ }^{43-45}$ may add usefully to the discriminability of a cognitive test package, but this possibility has not been formally explored. There is as yet no clinical application for a predictive test package with the level of discriminability reported here $(50-60 \%$ sensitivity with a $10 \%$ false positive rate), but this conclusion would change in the event of the introduction of a treatment with the ability to modify the disease course. Epidemiological studies have suggested that

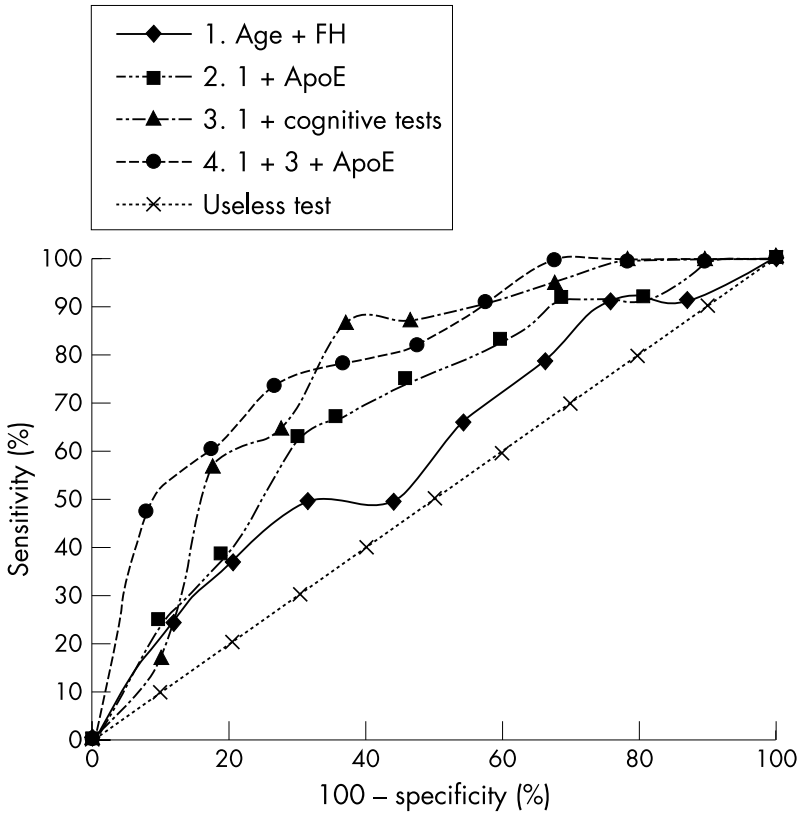

Areas under the ROC curves for each model predicting Alzheimer's disease and tests for the significance of the difference between them

Predictive model

$\operatorname{AUC}(95 \% \mathrm{Cl})$

Significance test

1. $\mathrm{FH}+$ age

$0.61(0.49$ to 0.73$)$

2. $\mathrm{FH}+$ age + APOE genotype

0.69 (0.59 to 0.79$)$

$2 \vee 1: p=0.16$

3. $\mathrm{FH}+$ age +

cognitive tests

0.77 (0.69 to 0.85$)$

$3 \vee 1: p=0.016$

$3 \vee 2: p=0.16$

4. $\mathrm{FH}+$ age +

cognitive tests +

$0.81(0.72$ to 0.90$)$

$4 \vee 3: p=0.28$

$4 \vee 2: p=0.048$ 


\section{REFERENCES}

1 Braak H, Braak E. Evolution of neuronal changes in the course of Alzheimer's disease. J Neural Transm 1998;53(suppl): 127-40.

2 Palmer K, Backman L, Winglad B, et al. Detection of Alzheimer's disease and dementia in the preclinical phase: population based cohort study. BMJ 2003;326:245-9.

3 Chen $\mathbf{P}$, Ratcliff $\mathrm{G}$, Belle $\mathrm{SH}$, et al. Cognitive tests that best discriminate between presymptomatic $A D$ and those who remain non demented. Neurology 2000;55:1847-53.

4 Elias MF, Beiser A, Wolf PA, et al. The preclinical phase of Alzheimer disease. A 22 year prospective study of the Framingham cohort. Arch Neurol 2000:57:808-13.

5 MRC Working Party. MRC Research Council Trial of treatment of hypertension in older adults: principal results. BMJ 1992;304:405-12.

6 Prince MJ. Predicting the onset of Alzheimer's disease using Bayes' theorem. Am J Epidemiol 1996;143:301-8.

7 Prince MJ, Cullen MC, Mann AH. Risk factors for Alzheimer's disease and dementia: a case-control study based on the MRC Elderly Hypertension Trial. Neurology 1994;44:97-104.

8 Prince M, Lovestone S, Cervilla J, et al. The association between APOE and dementia seems not to be mediated by vascular factors. Neurology 2000:54:397-402

9 Folstein MF, Folstein SE, McHugh PR. "Mini-mental state": a practical method for grading the cognitive state of patients for the clinician. J Psychiatr Res 1975;12:189-98.

10 Copeland JRM, Dewey ME, Griffith-Jones HM. A computerised psychiatric diagnostic system and case nomenclature for elderly subjects: GMS and AGECAT. Psychol Med 1986; 16:89-99.

11 Roth M, Tym E, Mountjoy CQ, et al. CAMDEX. A standardised instrument for the diagnosis of mental disorder in the elderly with special reference to the early detection of dementia. Br J Psychiatry 1986;149:698-709.

12 Broe GA, Akhtar AJ, Andrews GR, et al. Neurological disorders in the elderly at home. J Neurol Neurosurg Psychiatry 1976;39:361-6.

13 American Psychiatric Association. Diagnostic and statistical manual of mental disorders. Washington DC: AMA, 1994.

14 McKhann G, Drachman D, Folstein M, et al. Clinical diagnosis of Alzheimer's disease: report of the NINCDS-ADRDA Work Group under the auspices of Department of Health and Human Services Task Force on Alzheimer's Disease. Neurology 1984;34:939-44.

15 Roman GC, Tatemichi TK, Erkinjuntti T, et al. Vascular dementia: diagnostic criteria for research studies. Report of the NINDS-AIREN International Workshop. Neurology 1993;43:250-60.

16 Inglis J. A paired-associate learning test for use with elderly psychiatric patients. J Ment Sci 1959;105:440-3.

17 Reltan RM. Validity of the trail making test as an indication of organic brain damage. Percept Motor Skills 1959;8:271-6.

18 Nelson H, O'Connell A. Dementia. The estimation of pre-morbid intelligence levels using the new adult reading test. Cortex 1978;14:234-44.

19 Raven JC. Matrix tests. Mental Health 1940;1:10-18.

20 Hanley JA, McNeil BJ. The meaning and use of the area under a receiver operating characteristic (ROC) curve. Radiology 1982;143:29-36.

21 Hanley JA, McNeil BJ. A method of comparing the areas under receiver operating characteristic curves derived from the same cases. Radiology 1983;148:839-43.

22 Centor RM. A Visicalc program for estimating the area under a receiver operating characteristic (ROC) curve. Med Decis Making 1985;5:139-48.

23 Soininen HS, Scheltens P. Early diagnostic indices for the prevention of Alzheimer's disease. Ann Med 1998;30:553-9.

24 Bowen J, Teri L, Kukull W, et al. Progression to dementia in patients with isolated memory loss. Lancet 1997;349:763-5

25 Tierney MC, Szalai JP, Snow WG, et al. Prediction of probable Alzheimer's disease in memory-impaired patients: a prospective longitudinal study. Neurology 1996:46:661-5.

26 Masur DM, Fuld PA, Blau AD, et al. Predicting development of dementia in the elderly with the selective reminding test. J Clin Exp Neuropsychol 1990; 12:529-38
27 Chen P, Ratcliff G, Bell S, et al. Cognitive tests that best discriminate between presymptomatic $A D$ and those who remain nondemented. Neurology 2000;55: 1847-53

28 Palmer K, Bäckman L, Winblad B, et al. Detection of Alzheimer's disease and dementia in the preclinical phase: population based cohort study. $B M$ 2003;326:245-50

29 Backman L, Small BJ, Fratiglioni L. Stability of the preclinical episodic memory deficit in Alzheimer's disease. Brain 2001;124:96-102.

30 Deary IJ, Whalley U, St Clair D, et al. The influence of the epsilon 4 allele of the apolipoprotein $\mathrm{E}$ gene on childhood $I Q$, nonverbal reasoning in old age, and lifetime cognitive change. Intelligence 2003;31:85-92.

31 Turic D, Fisher PJ, Plomin R, et al. No association between apolipoprotein E polymorphisms and general cognitive ability in children. Neurosci Lett 2001;299:97-100

32 Deary IJ, Whiteman MC, Pattie A, et al. Cognitive change and the APOE e4 allele. Nature 2002;418:932.

33 Cervilla JA, Prince $M$, Joels $S$, et al. Long term determinants of cognitive outcome in a cohort of elderly hypertensives. Br J Psychiatry 2000; 177:66-71

34 Yip AG, Brayne C, Easton D, et al. Apolipoprotein E4 is only a weak predictor of dementia and cognitive decline in the general population. Am J Med Genet 2002;39:639-43.

35 Wilson RS, Schneider JA, Barnes LL, et al. The apolipoprotein E epsilon 4 allele and decline in different cognitive systems during a 6 -year period. Arch Neurol 2002;59:1154-60.

36 Prince MJ. Is chronic low-level lead exposure in early life an etiological factor in Alzheimer's disease? Epidemiology 1998;9:618-21.

37 Snowdon DA, Kemper SJ, Mortimer JA, et al. Linguistic ability in early life and cognitive function and Alzheimer's disease in late life. JAMA 1996;275:528-32.

38 Stern Y, Gurland B, Tatemichi TK, et al. Influence of education and occupation on the incidence of Alzheimer's disease. JAMA 1994;271:1004-10.

39 Stern Y, Tang MX, Denaro J, et al. Increased risk of mortality in Alzheimer's disease patients with more advanced educational and occupational attainment. Ann Neurol 1995;37:590-5.

40 Hirono N, Hashimoto M, Yasuda M, et al. The effect of APOE epsilon 4 allele on cerebral glucose metabolism in $A D$ is a function of age at onset. Neurology 2002:58:743-50.

41 Relkin NR, Kwon YJ, Tsai J, et al. The National Institute on Aging/Alzheimer's Association recommendations on the application of apolipoprotein $\mathrm{E}$ genotyping to Alzheimer's disease. Ann NY Acad Sci 1996;802:149-76.

42 American College of Medical Genetics/American Society of Human Genetics Working Group on ApoE and Alzheimer disease. Statement on use of apolipoprotein E testing for Alzheimer disease. JAMA 1995;274:1627-9.

43 Jack $C R$, Petersen RC, $X_{U} Y$, et al. Rate of medial temporal lobe atrophy in typical aging and Alzheimer's disease. Neurology 1998;51:993-9.

44 Reiman EM, Uecker A, Caselli RJ, et al. Hippocampal volumes in cognitively normal persons at genetic risk for Alzheimer's disease. Ann Neurol 1998;44:288-91.

45 Bottino CM Almeida OP. Can neuroimaging techniques identify individuals at risk of developing Alzheimer's disease? Int Psychogeriatr 1997;9:389-403.

46 Andersen K, Launer $\mathrm{L}, \mathrm{OH} A$, et al. Do nonsteroidal anti-inflammatory drugs decrease the risk for Alzheimer's disease? The Rotterdam Study. Neurology 1995:45: 1441-5.

47 Stewart WF, Kawas C, Corrada M, et al. Risk of Alzheimer's disease and duration of NSAID use. Neurology 1997;48:626-32.

48 Yaffe K, Sawaya G, Lieberburg l, et al. Estrogen therapy in postmenopausal women: Effects on cognitive function and dementia. JAMA 1998:279:688-95.

49 Asthana S, Baker LD, Craft S, et al. High-dose estradiol improves cognition for women with $A D$ - results of a randomized study. Neurology 2001; 57:605-12.

50 Schenk D, Barbour R, Dunn W, et al. Immunization with amyloid-beta attenuates Alzheimer-disease-like pathology in the PDAPP mouse. Nature 1999;400:116-17. 